\title{
Acute necrotizing colitis due to sigmoid colon cancer
}

\author{
Hiroki Matsunaga ${ }^{1,2}$, Dai Shida $^{3 *}$, Makoto Kamesaki ${ }^{2}$ and Yuichi Hamabe ${ }^{2}$
}

\begin{abstract}
When obstructive colitis becomes fulminant, it is known as 'acute necrotizing colitis'. We report a rare case of acute necrotizing colitis due to sigmoid colon cancer, in which shock status occurred within ten hours of onset. A 79-year-old female with acute abdominal pain was transported to our hospital with acute shock. Abdominal enhanced computed tomography revealed thickening of the wall of the sigmoid colon and marked dilation of the proximal colon. Emergency surgery was performed with the intraoperative findings of severe sigmoid colon stenosis and proximal dilation of the colon without perforation, and a large volume of putrid ascitic fluid. The intestine was proximally dilated and black in color, from the sigmoid colon to the ileum $60 \mathrm{~cm}$ proximal to the terminal ileum, suggesting acute necrosis. Total colectomy with $80 \mathrm{~cm}$ resection of terminal ileum and ileostomy was performed. Whereas acute necrotizing colitis is a rare condition and its etiology remains obscure, the chronic ischemic state must play some role. Our patient was of advanced age and had diabetes mellitus and hypertension. These factors might lead to a chronic ischemic state of the bowel due to arteriosclerosis. In addition to the underlying condition, massive bacterial reflux into the ileum from the colon might cause the capillary vasoconstriction of the bowel that led to her critical state.
\end{abstract}

Keywords: Necrotizing colitis, Fulminant obstructive colitis, Obstructed colon cancer

\section{Background}

Obstructive colitis is a condition defined as nonspecific inflammatory lesions of the colon, such as erosion and ulceration, proximal to a completely or partially obstructive lesion [1-3]. Obstructive colitis, although rare, can become fulminant, which is then known as 'acute necrotizing colitis' $[4,5]$. Extensive colonic gangrene associated with colonic obstruction is a serious complication requiring emergency surgery. Only few cases of acute necrotizing colitis due to colon cancer are reported in the English medical literature [6-8].

We experienced a case of acute necrotizing colitis and ileitis due to colon cancer with a rapid clinical course, in which shock status occurred within ten hour of initial symptoms. The patient was saved only after intensive care and two emergency operations, thus emphasizing the importance of these interventions in such cases.

\footnotetext{
* Correspondence: dshida-tky@umin.ac.jp

${ }^{3}$ Colorectal Surgery Division, National Cancer Center Hospital, 5-1-1 Tsukiji, Chuo-ku, Tokyo 1040045, Japan

Full list of author information is available at the end of the article
}

\section{Case presentation}

A 79-year-old female with acute, gradually worsening abdominal pain requested emergency services. By the time of their arrival, she had collapsed. She was transported to our tertiary emergency medical center. Physical examination on admission revealed a Glasgow coma scale of E4V5M6, blood pressure $80 / 50 \mathrm{mmHg}$, pulse $88 / \mathrm{min}$, respiratory rate $28 /$ minute, temperature $36.9^{\circ} \mathrm{C}$, and $\mathrm{O}_{2}$ saturation $100 \%$ (with $10 \mathrm{l}$ reservoir mask). Acute shock, abdominal distension and tenderness, and muscular guarding were also noted. Laboratory results showed a mild increase in the inflammatory response: leukocyte count $7.6 \times 10^{3} / \mu \mathrm{l}$, C-reactive protein $2.70 \mathrm{mg} / \mathrm{dl}$, hemoglobin $15.3 \mathrm{mg} / \mathrm{dl}$, and blood urea nitrogen $41 \mathrm{mg} / \mathrm{dl}$, indicative of severe dehydration. Abdominal enhanced computed tomography (CT) revealed thickening of the sigmoid colon and marked dilation of the proximal intestine from the ileum to the sigmoid colon (Figure 1). Emergency colonoscopy showed an advanced colorectal carcinoma with severe and complete circumferential stenosis (Figure 2). Respiratory status, consciousness, and circulatory status deteriorated gradually. Blood gas analysis showed $\mathrm{pH}$ 6.967, $\mathrm{PaO}_{2} 48.6 \mathrm{mmHg}$,

\section{Biomed Central}

(c) 2014 Matsunaga et al.; licensee BioMed Central Ltd. This is an open access article distributed under the terms of the Creative Commons Attribution License (http://creativecommons.org/licenses/by/2.0), which permits unrestricted use, distribution, and reproduction in any medium, provided the original work is properly cited. 


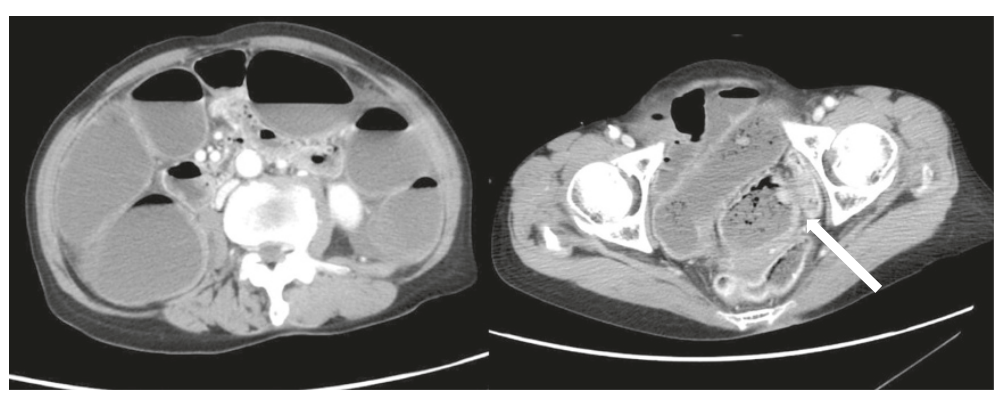

Figure 1 Abdominal enhanced computed tomography scan showing a large tumor in the sigmoid colon (arrow) and dilation of the colon and small intestine.

and $\mathrm{PaCO}_{2} 77.0 \mathrm{mmHg}$, indicating ventilatory failure. We thus performed emergency laparotomy under a diagnosis of fulminant obstructive colitis due to sigmoid colon cancer. Intraoperative findings were severe stenosis of the sigmoid colon and proximal dilation without perforation, and a large volume of putrid ascitic fluid. The intestine was dilated proximally and colored black from the sigmoid colon to $60 \mathrm{~cm}$ proximal to the terminal ileum, suggesting acute necrosis without major vessel occlusion. We performed total colectomy with $80 \mathrm{~cm}$ resection of terminal ileum and ileostomy in an operating time of two and a half hours. Macroscopic findings showed a tumor $(45 \times 35 \mathrm{~mm})$ in the sigmoid colon causing colonic obstruction. The bowel, from the sigmoid colon to $60 \mathrm{~cm}$ proximal to the terminal ileum, was totally necrotized (Figure 3). Normal mucosa was observed between the necrotic lesion and the tumor in the sigmoid colon, which was compatible with a diagnosis of obstructive colitis (Figure 3). Histopathologic diagnosis was moderately differentiated adenocarcinoma and was evaluated as T3NOM0 stage II according to the American Joint Committee on Cancer (AJCC) staging system.

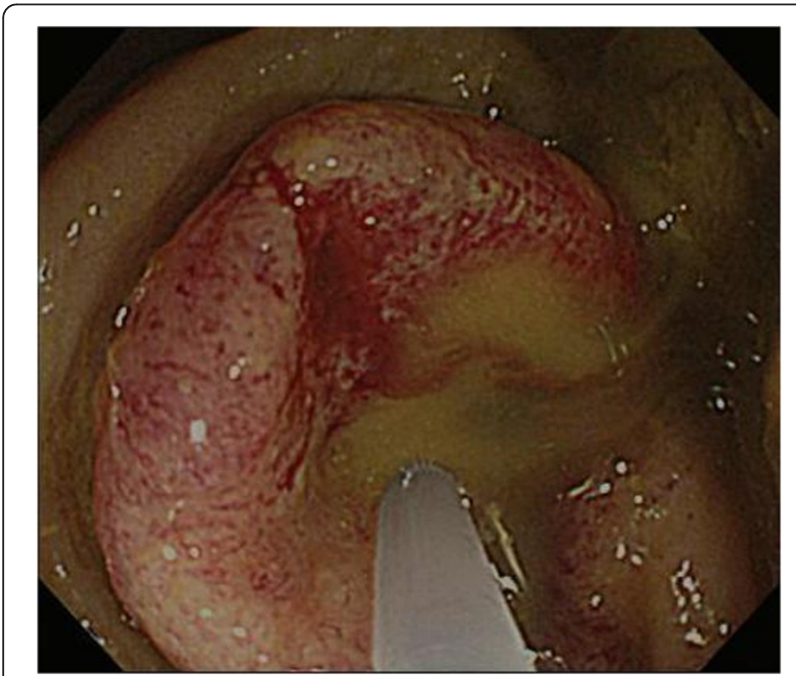

Figure 2 Colonoscopy showing an obstructive tumor in the sigmoid colon.
After surgery, intensive care, including mechanical ventilation, continuous hemodiafiltration, polymyxin B hemoperfusion, and blood transfusion, was continued to address circulatory failure and acute renal failure due to sepsis. The patient's general condition improved gradually, and catecholamine administration was withdrawn on postoperative day 5 . On postoperative day 8 , perforation of the small intestine near the stoma occurred. We performed a further emergency surgery to create a new ileostomy. The patient's general condition improved, and she was then transferred to a rehabilitation hospital on postoperative day 71 .

\section{Conclusions}

The incidence of obstructive colitis is known to be $0.3 \%$ to $3.1 \%$ of all colorectal carcinomas [1,3]; however, it remains an uncommon and troublesome disease. The features of obstructive colitis are as follows: (1) an ulceroinflammatory lesion present on the oral side of the obstruction site; (2) the anal side of the obstruction site is macroscopically and histologically normal; and (3) normal mucosa is present between the obstruction and ulceration sites, and its border is clear [2]. The findings in our case were according to these criteria.

Among obstructive colitis cases, few develop fulminating gangrene of the colon, an entity is termed 'necrotizing colitis' [4], the etiology of which remains unknown. Increasing intraluminal pressure may affect colonic blood flow, and in closed-loop colonic obstruction without perforation, mucosal ischemia may be the primary event leading to massive colonic gangrene. Bacterial proliferation in the obstructed fecal material may be a factor [5], and hypoxia may also play a key role. Hypoxia stimulates the germination of spores and bacterial growth, which then progresses rapidly to produce exotoxins that destroy and liquefy surrounding tissue, leading to rapid spread of the disease [5]. Our patient was of advanced age and had diabetes mellitus and hypertension. These factors might lead to chronic ischemic state of the bowel due to arteriosclerosis. In addition to the colitic condition, massive bacterial reflux into the ileum from the 


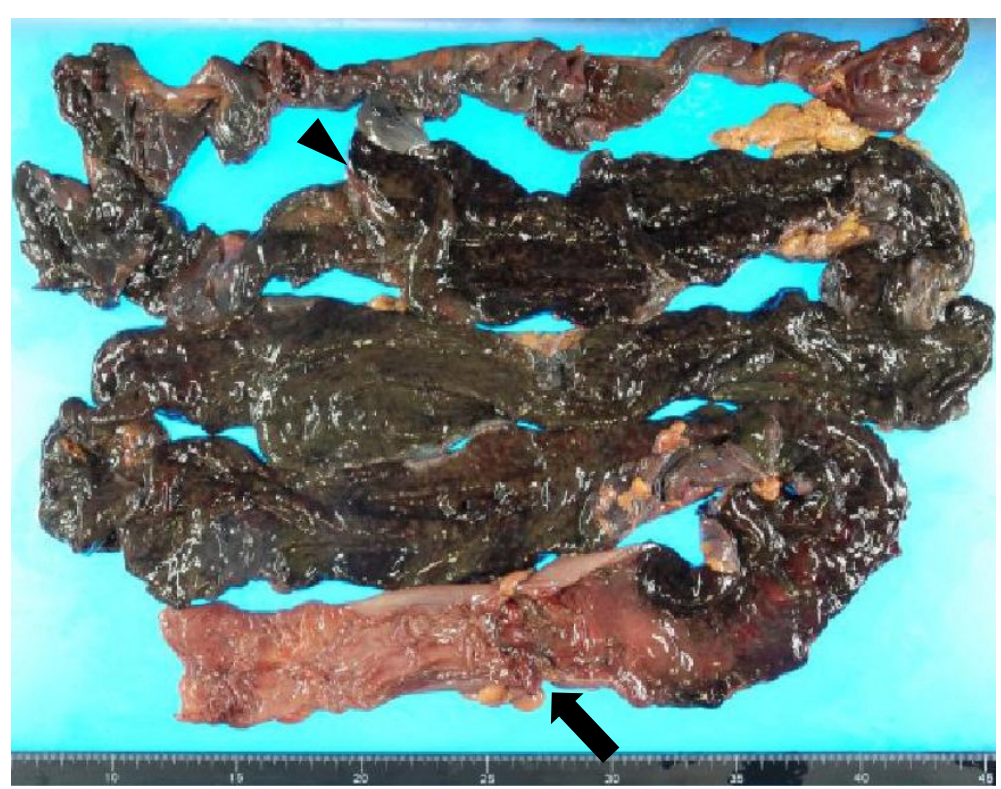

Figure 3 Macroscopic appearance of the resected intestine. Arrow indicates colon cancer, and arrow head indicates the ileocecal valve.

colon caused the capillary vasoconstriction of the bowel and that led to her critical condition.

Since the present case followed a rapid clinical course and entered shock status within ten hours, we performed emergency surgery. At the tertiary emergency room, rapid 2 l-infusion was initially administered and at that time, the patient was responding to some extent. So, enhanced CT and colonography were examined. With colonography, a transanal drainage tube was inserted to the proximal dilated bowel through the tumor. Because her vital signs deteriorated in spite of these treatments, we performed the emergency operation. In our case, examination of enhanced CT and colonography did not change the final management, and might simply have delayed the operation. Urgent laparotomy might, therefore, be the better choice in septic shock and hemodynamically unstable conditions with clear peritoneal signs on arrival.

In this situation, it is vital to resect the entire necrotic intestine, following which the status of the mucosa of the proximal margin and proximal remnant bowel should be checked. If any ischemic change is observed in the proximal remnant bowel mucosa, further colonic tissue should be resected proximally until a healthy mucosal margin is achieved [1]. In the present case, during the first operation, we confirmed that mucosal status at the proximal margin was normal. However, on postoperative day 8 , the delayed perforation that occurred near this area suggested that acute necrotizing colitis had been progressive from the time of the first operation. Therefore, it would seem advisable to resect more intestine than that indicated solely by macroscopic findings.
In summary, we report a case of acute necrotizing colitis due to sigmoid colon cancer, in which shock status occurred 10 hours from onset. Emergency surgery and intensive care were essential in saving the patient's life.

\section{Consent}

Written informed consent was obtained from the patient for publication of this case report and any accompanying images. A copy of the written consent is available for review by the Editor-in-Chief of this journal.

\section{Abbreviations}

AJCC: American Joint Committee on Cancer; CT: computed tomography.

\section{Competing interests}

The authors declare that they have no competing interests.

\section{Author' contributions}

$\mathrm{HM}, \mathrm{MK}$ and $\mathrm{YH}$ collected the data, performed the treatment, and wrote the paper. DS was responsible for writing the paper and for its supervision. All authors read and approved the final manuscript.

\section{Acknowledgements}

The authors acknowledge all the nurses who took care of our patient.

\section{Author details}

${ }^{1}$ Department of Surgery, Tokyo Metropolitan Bokutoh Hospital, 4-23-15 Koto-bashi, Sumida-ku, Tokyo 1308575, Japan. ${ }^{2}$ Tertiary Emergency Medical Center, Tokyo Metropolitan Bokutoh Hospital, 4-23-15 Koto-bashi, Sumida-ku, Tokyo 1308575, Japan. ${ }^{3}$ Colorectal Surgery Division, National Cancer Center Hospital, 5-1-1 Tsukiji, Chuo-ku, Tokyo 1040045, Japan.

Received: 13 December 2012 Accepted: 18 January 2014

Published: 27 January 2014

\section{References}

1. Chang HK, Min BS, Ko YT, Kim NK, Kim H, Cho CH: Obstructive colitis proximal to obstructive colorectal carcinoma. Asian J Surg 2009, 32:26-32. 
2. Glotzer DJ, Gpihl BG: Experimental obstructive colitis. Arch Surg 1966, 92:1-8.

3. Tsai MH, Yang YC, Leu FJ: Obstructive colitis proximal to partially obstructive colonic carcinoma: a case report and review of the literature. Int J Colorectal Dis 2004, 19:268-272.

4. Killingback MJ, Williams KL: Necrotizing colitis. Br J Surg 1961, 49:175-185.

5. Teasdale C, Mortensen NJ: Acute necrotizing colitis and obstruction. Br J Surg 1983, 70:44-47.

6. Dosik GM, Luna M, Valdivieso M, McCredie KB, Gehan EA, Gil-Extremera B, Smith TL, Bodey GP: Necrotizing colitis in patients with cancer. Am J Med 1979, 67:646-656.

7. Harada T, Umezawa I, Mogami K, Itoh Z: Acute gangrenous colitis proximal to obstructive cancer of the sigmoid colon. Jpn J Surg 1975, 5:39-47.

8. Moriwaki Y, Sugiyama M, Toyoda H, Kosuge T, Arata S, Iwashita M, Suzuki N: Lethal obstructive colitis: how and when patients with colonic obstruction should be prevented from falling into a lethal condition. Hepatogastroenterology 2009, 56:659-662.

doi:10.1186/1477-7819-12-19

Cite this article as: Matsunaga et al:: Acute necrotizing colitis due to sigmoid colon cancer. World Journal of Surgical Oncology 2014 12:19.

\section{Submit your next manuscript to BioMed Central and take full advantage of:}

- Convenient online submission

- Thorough peer review

- No space constraints or color figure charges

- Immediate publication on acceptance

- Inclusion in PubMed, CAS, Scopus and Google Scholar

- Research which is freely available for redistribution 